\title{
The Role of Health-related Behaviors in Gestational Weight Gain among Women with Overweight and Obesity: A Cross-sectional Analysis
}

\section{Papel dos comportamentos relacionados à saúde no ganho de peso gestacional em mulheres com sobrepeso e obesidade: Um estudo transversal}

\author{
Daiane Sofia Morais Paulino ${ }^{10}$ Maira Pinho-Pompeu ${ }^{10}$ Fernanda Raikov ${ }^{1(1)}$ \\ Juliana Vasconcellos Freitas-Jesus ${ }^{10}$ Helymar Costa Machado ${ }^{10}$ Fernanda Garanhani Surita1(0) \\ ${ }^{1}$ Department of Obstetrics and Gynecology, Universidade Estadual de \\ Campinas, Campinas, SP, Brazil \\ Address for correspondence Fernanda Garanhani Surita, MD, \\ Department of Obstetrics and Gynecology, Universidade Estadual de \\ Rev Bras Ginecol Obstet 2020;42(6):316-324.

\begin{abstract}
Keywords

- health-related behaviors

- gestational weight gain

- overweight

- obesity

Objective To evaluate the influence of health-related behaviors including food intake, physical activity, sleep time, smoking habits, stress, depression, and optimism on excessive gestational weight gain (GWG) among women with overweight and obesity. Methods A cross-sectional study was conducted at the Women's Hospital of the Universidade de Campinas, Campinas, state of São Paulo, Brazil, with 386 mediate postpartum women that fit the inclusion criteria of $\geq 19$ years old, first prenatal care visit at or before 14 weeks, and single live baby. Dietary habits, physical exercise practice, sleep duration, smoking and alcohol habits were self-reported. Psychosocial history was evaluated using the Edinburgh Postpartum Depression Scale (EPDS), Perceived Stress Scale (PSS), and Life Orientation Test-Revised (LOT-R). Sociodemographic, obstetric, anthropometric, and neonatal data were retrieved from medical records. Descriptive statistics and stepwise logistic regression were performed.

Results The prevalence of overweight and obesity was $29.27 \%$ and $24.61 \%$, respectively, according to the body mass index (BMI). Excessive GWG was observed in $47.79 \%$ of women with overweight and in $45.26 \%$ of women with obesity. Excessive GWG among overweight and obese women was associated with inadequate vegetable and bean consumption (odds ratio $[\mathrm{OR}]=2.95,95 \%$ confidence interval $[\mathrm{CI}]: 1.35-6.46$ and $\mathrm{OR}=1.91 ; 95 \% \mathrm{Cl}: 1.01-3.63$, respectively) and stress $(\mathrm{OR}=1.63 ; 95 \% \mathrm{Cl} 1.01-2.64)$. After adjustment by maternal age, multiparity, sleep duration, smoking, and alcohol intake, we found that stress (PSS $\geq 20$ ) was associated with excessive GWG in women with overweight or obesity (OR: 1.75; 95\%Cl: 1.03-2.96).

Conclusion Among women with overweight and obesity, stress is the main variable associated with excessive GWG. Inadequate vegetables and beans consumption also showed association with excessive GWG.
\end{abstract}

received

December 15, 2019

accepted

April 2, 2020
DOI https://doi.org/

10.1055/s-0040-1712132. ISSN $0100-7203$.
Copyright $\odot 2020$ by Thieme Revinter

Publicações Ltda, Rio de Janeiro, Brazil
License terms

(c) $(1$ 


\section{Resumo}

\section{Palavras-chave}

- comportamentos relacionados à saúde

- ganho de peso gestacional

- sobrepeso

- obesidade
Objetivo Avaliar a influência de comportamentos relacionados à saúde: ingestão alimentar, atividade física, tempo de sono, tabagismo, estresse, depressão e otimismo no ganho de peso gestacional (GPG) excessivo em mulheres com sobrepeso e obesidade.

Métodos Estudo transversal no Hospital da Mulher, Universidade de Campinas, Campinas, SP, Brasil, com 386 mulheres no puerpério mediato, $\geq 19$ anos, primeira consulta pré-natal até 14 semanas e cuja gestação resultou em neonato vivo. Os comportamentos relacionados à saúde foram autorreferidos. História psicossocial foi avaliada usando: Escala de Depressão Pós-Parto de Edimburgo (EPDS, na sigla em inglês), Escala de Estresse Percebido (PSS, na sigla em inglês) e Teste de Orientação à Vida-Revisado (LOT-R, na sigla em inglês). Dados sociodemográficos, obstétricos, antropométricos e neonatais foram obtidos dos prontuários médicos. Realizou-se análises descritivas e regressão logística.

Resultados A prevalência de sobrepeso e obesidade foi de $29,27 \%$ e de $24,61 \%$, respectivamente. Ganho de peso gestacional excessivo foi observado em $47,79 \%$ das mulheres com sobrepeso e em $45,26 \%$ das mulheres com obesidade. $O$ consumo inadequado de verduras e feijão (razão de probabilidade $[O R]=2,95$; índice de confiança [IC] 95\%: 1,35-6,46 e OR=1,91; IC95\%: 1,01-3,63, respectivamente) e estresse $(O R=1,63$; IC95\%: 1,01-2,64) foram associados ao GPG excessivo em mulheres com sobrepeso e obesidade. Análises ajustadas para idade materna, multiparidade, duração do sono, tabagismo e ingestão de álcool mostraram que o estresse (PSS $\geq 20$ ) associou-se ao GPG excessivo em mulheres com sobrepeso e obesidade (OR $=1.75 ; 95 \% \mathrm{Cl}: 1.03-2.96)$.

Conclusão Entre mulheres com sobrepeso e obesidade, o estresse foi a principal variável associada ao GPG excessivo. O consumo inadequado de verduras e feijão também se associou com o GPG excessivo.

\section{Introduction}

Obesity and overweight prevalence have increased dramatically over the past 30 years among reproductive-age women. ${ }^{1}$ Obesity in the gestational period has consistently been associated with adverse health outcomes for mothers and their children, including epigenetic alterations and metabolic disorders in offspring. ${ }^{2}$

Gestational weight gain (GWG) is an important modulator of perinatal outcomes that is independent of prepregnancy nutritional status. ${ }^{3}$ In this way, it is described that excessive GWG increases the risk of gestational diabetes mellitus, hypertensive syndrome, and cesarean section (C-section). ${ }^{4}$ Besides that, excessive GWG has been correlated with postpartum weight retention, obesity, and future metabolic disorders in women. ${ }^{4}$ In the children, excessive GWG is associated with macrosomia and increased adiposity in infants, whereas insufficient GWG is associated with lower birthweight and preterm birth. ${ }^{3,4}$

Despite the adverse effects of excessive GWG, the influence of health-related behaviors on GWG is not completely understood. The association between modifiable behavioral factors such as dietary habits, physical activity, and psychological states with excessive GWG is controversial. ${ }^{5-7}$
In this sense, a systematic review about the effectiveness of diet or exercise, or both interventions for preventing excessive GWG demonstrated that diet or exercise reduced the frequency of excessive GWG by $20 \%$ (relative risk $[R R]=0.8 ; 95 \%$ confidence interval [CI]: 0.73-0.87) while minimally increasing the risk for inadequate GWG $(\mathrm{RR}=1.14 ; 95 \% \mathrm{Cl}: 1.02-1.27) .^{8}$

The association between short sleep duration (SSD) and obesity is well-described, and the negative influence of SSD on energy balance regulation and its potential to impact on weight status has also been established. ${ }^{9,10}$ Furthermore, during pregnancy, the prevalence of poor sleep quality was higher among overweight and obese women. ${ }^{11}$

Similarly, alcohol consumption and smoking are also correlated with energy metabolism. It was demonstrated that smoking cessation was associated with greater GWG. ${ }^{12}$ However, in animals, tobacco and alcohol exposure reduced GWG. ${ }^{13}$

In relation to the psychological factors, it was demonstrated that, among women with obesity and adequate GWG, emotional conflicts arising from fear of their own and their baby's life due to the inherent risks of obesity in this life cycle appear to be a potentiating factor for changing habits. ${ }^{14}$

Therefore, understanding the behaviors that influence GWG among women with overweight and obesity is crucial to developing behavioral change strategies and specific guidelines 
for weight control and prenatal education. Pregnancy is also an important period that affects maternal weight trajectory and fetal metabolic programming. The aim of the present study was to evaluate the effects of health-related behaviors (diet, physical activity, sleep duration, smoking, alcohol intake, and psychological factors) on excessive GWG among women that were overweight or obese.

\section{Methods}

A cross-sectional study was conducted at the Women's Hospital of the Universidade de Campinas, Campinas, state of São Paulo, Brazil. The eligibility criteria were $\geq 19$ years old, antenatal care starting in or before 14 weeks of gestation, and a pregnancy that resulted in a live singleton birth. The present study was approved by the Ethics Committee of the Universidade de Campinas and the Brazilian National Board of Health, CAAE 44630615.3.0000.5404. Data were collected after informed consent was obtained from all participants.

The required sample size was calculated based on the associations between modifiable health-related behaviors and excessive or insufficient GWG reported by McDonald et al. ${ }^{15}$ Assuming a significance level of $5 \%$ and power of $90 \%$, the necessary sample size was 386 women.

Sociodemographic characteristics (maternal age and education level), obstetric history, anthropometric data, and neonatal data were collected from medical records. Education level was classified as elementary school (up to 9 years of study); high school (up to 12 years of study); college, university or advanced degree ( $>12$ years of study). The body mass index (BMI) early in pregnancy was calculated from height and weight at the first prenatal visit (up to 14 weeks) and classified according to the criteria of the World Health Organization (WHO). The final weight was defined as the weight at admission for delivery. Gestational weight gain was calculated as the weight difference between final weight and weight at the first prenatal visit, and was evaluated according to the guidelines of the Institute of Medicine. ${ }^{16}$ The adequacy of birthweight was classified according to the INTERGROWTH-21st Project Study $^{17}$ recommendations, which consider the gestational age and gender and categorize the adequacy of birthweight as small for gestational age birthweight (SGA), adequate for gestational age birthweight (AGA) or large for gestational age birthweight (LGA).

The variables related to the adoption of health-related behaviors during pregnancy were collected in the mediate postpartum (1-3 days after delivery). Physical exercise practice, sleep duration, alcohol intake and smoking habits during the pregnancy were captured using a specially designed self-report questionnaire and the women referred about their habits during the entire gestational period.

Dietary habits were assessed once by a qualitative frequency questionnaire, ${ }^{18}$ which provides data on maternal food intake patterns based on healthy and unhealthy eating markers. The use of eating markers during pregnancy is recommended by the Brazilian Ministry of Health. ${ }^{19}$ Women were questioned regarding the habitual consumption frequency of foods that are recognized as healthy (fruits, vegetables, beans, and milk) and unhealthy (soft drinks, meat, and family oil consumption) eating markers. The intake of these foods was obtained as never or less than once/week; 1-3 times/week; 3-6 times/week or every day. The variable "family oil consumption" was obtained as numbers of tins of oil consumed by the family during a month.

Psychosocial issues were evaluated using a 10 -item version of the Edinburgh Postpartum Depression Scale (EPDS), ${ }^{20}$ a 10item version of the Perceived Stress Scale (PSS), ${ }^{21}$ and the Life Orientation Test-Revised (LOT-R). ${ }^{22}$ The EPDS is a depression screening tool in which scores $\geq 10$ indicate possible depression. Perceived Stress Scale responses were scored using a 5point scale (coded $0-4$ ) and summed; scores $\geq 20$ indicated a high level of perceived stress. The LOT-R consists of 6 items, and individual items scores are summed to yield a total score (range 6-30); high scores indicated optimism and low scores indicated pessimism. We treated the LOT-R score as a continuous variable. Moreover, we followed the time frame suggested in each instrument, which is "last 7 days" for the EPDS, "last month" for the PSS, and "usually" for the LOT-R.

\section{Data Analysis}

Categorical variables were described using frequencies and percentages, whereas continuous variables were described using mean and standard deviation (SD). Logistic regression analysis was used to identify independent factors associated with excessive GWG considering health-related behaviors, as well as sociodemographic and obstetric variables in pregnant women with obesity and overweight compared with all other women in the sample (i.e., pregnant women with obesity and overweight with adequate and insufficient GWG plus eutrophic and underweight pregnant women with any GWG category). We also conducted a univariate and multivariate analysis (stepwise) adjusted for maternal age, multiparity, sleep hours, smoking status, and alcohol intake, considering that these factors are related to energy metabolism. The significance level for all tests was $5 \%$, and they were performed using SAS Statistical Analysis System for Windows, version 9.2 (SAS Institute Inc., Cary, NC, USA). All items on the STROBE checklist for a cross-sectional study have been included in the present manuscript.

\section{Results}

The sample comprised 386 women with a mean age of 28.31 years old $(S D=5.68)$ and a mean BMI of $27.98 \mathrm{~kg} / \mathrm{m}^{2}$ $(\mathrm{SD}=3.66)$. The combined prevalence of overweight and obesity was $53.88 \%$. Obstetric complications were present in $47.13 \%$ of participants, with gestational diabetes mellitus (15.36\%), hypertensive disorder (13.28\%), and/or urinary infection (10.41\%) occurring most frequently. - Table 1 displays the BMIs as well as sociodemographic, obstetric, and neonatal variables of the participants.

Gestational weight gain was insufficient for $31.09 \%$, adequate for $31.61 \%$, and excessive for $37.31 \%$. Excessive GWG among overweight and obese women was $47.79 \%$ and $45.26 \%$ respectively. - Fig. 1 shows GWG adequacy according to maternal prepregnancy BMI. 
Table 1 Socio-demographic and obstetric characteristics, prepregnancy body mass index, and perinatal outcomes for the whole sample

\begin{tabular}{lll}
\hline Variable $(n=386)$ & Mean & SD \\
\hline Maternal age (years old) & 28.41 & \pm 0.28 \\
BMI at first prenatal visit $\left(\mathrm{kg} / \mathrm{m}^{2}\right)$ & 27.98 & \pm 3.66 \\
& $n$ & $\%$
\end{tabular}

Educational level*

Elementary school 85

High school

College, university, 62

or advanced degree

Number of pregnancies

1

$\geq 2$

Delivery Mode

C-section

Vaginal

209

45.85

BMI at first prenatal visit $\left(\mathrm{kg} / \mathrm{m}^{2}\right)$

$<18.5$

16

54.14

18.5 a 24.9

16

4.15

25 a 29.9

41.97

$\geq 30$

29.27

24.61

Pre-pregnancy NCD

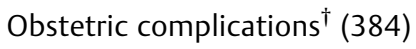

Diabetes mellitus

Hypertensive disorder

15.36

Urinary infection

Other

Adequacy of birthweight ${ }^{£}$

$\begin{array}{lll}\text { SGA } & 34 & 8.81 \\ \text { AGA } & 297 & 76.94 \\ \text { LGA } & 55 & 14.25\end{array}$

Apgar in the fifth minute

\begin{tabular}{lll}
$<7$ & 1 & 0.26 \\
$\geq 7$ & 385 & 99.74 \\
\hline
\end{tabular}

Abbreviations: AGA: Adequate-for-gestational-age; BMI: Body mass index, LGA: large-for-gestational-age; NCD: non-communicable disease. SGA: small-for-gestational-age.

${ }^{\dagger} 2$ missing data.

*4 missing data.

${ }^{\mathrm{E}} 9$ missing data. Data were presented as frequencies (n) and percentages (\%).

Approximately $48 \%$ of the participants reported daily fruit and vegetable intake, $44.24 \%$ reported daily beans intake, and $63.73 \%$ reported daily intake of milk and dairy products. The majority of women (64.94\%) reported daily consumption of meat.

More than half of the sample (57.03\%) reported not practicing physical activity during pregnancy. Most women
(91.91\%) did not drink any alcoholic beverages during pregnancy. A total of 64 women (16.8\%) reported some tobacco use during pregnancy, while 24 of these women (6.2\%) reported smoking throughout pregnancy.

Sleeping $<7$ hours per night before and during early pregnancy was reported by $38.12 \%$ and $32.90 \%$ of participants, respectively. Most women (59.37\%) also reported sleeping $<7$ hours during the final trimester of pregnancy.

Less than half of the women (40.68\%) scored $>10$ on the EPDS, $35.29 \%$ had PSS scores indicative of high perceived stress (PSS $\geq 20$ ), and the mean LOT-R score was $15.67 \pm 3.22$. A detailed sample distribution for the healthrelated behaviors is presented in - Table 2 .

Logistic regression analysis was conducted to evaluate the risk factors for excessive GWG among women with overweight and obesity when compared with those with adequate and insufficient GWG. The results are described in - Table 3.

We also performed univariate and multivariate logistic regression analysis to assess the risk factors for excessive GWG among women with overweight and obesity, after adjustment for maternal age, multiparity, sleep duration, smoking and alcohol intake (-Table 4 and -Table 5). Univariate logistic regression analysis showed that inadequate consumption of vegetables and beans (no intake or intake less than once per week) and stress were associated with excessive GWG among women with overweight and obesity.

Multivariate stepwise logistic regression adjusted by maternal age, multiparity, sleep duration, smoking, and alcohol intake demonstrates that stress (PSS $\geq 20$ ) approximately doubles the likelihood of excessive GWG in women with overweight or obesity (OR = 1.75; 95\%CI: 1.03-2.96) (- Table 5).

\section{Discussion}

The present study identified that stress is the main variable associated with excessive GWG in women that were obese or overweight. Low vegetable and beans consumption during pregnancy (no intake or intake less than once per week) also showed a strong association.

In relation to stress due to psychological factors, one study recently demonstrated that lower reported stress was associated with a greater likelihood of pregnant women achieving adequate GWG. ${ }^{23}$ In contrast to these findings, another study found no association between stress and excessive GWG. ${ }^{24}$ Race/ethnicity and socioeconomic status were described as determinants of maternal stress, while parental stress negatively affected quality of life among women. ${ }^{25}$

The association between dietary patterns and diet quality with GWG has been previously described; ${ }^{26,27}$ however, the results remain controversial. While one study demonstrated that women who consumed at least three servings of fruits and vegetables per day presented less weight gain, ${ }^{27}$ another study found no relationship between vegetable and fruit consumption and GWG. ${ }^{28}$

The majority of our sample reported not eating beans every day. This result is in agreement with the last Household Budget Survey that indicated the decreased consumption of foods considered healthy and popular in Brazilian culture, 
The Role of Health-related Behaviors in Gestational Weight Gain among Women with Overweight and

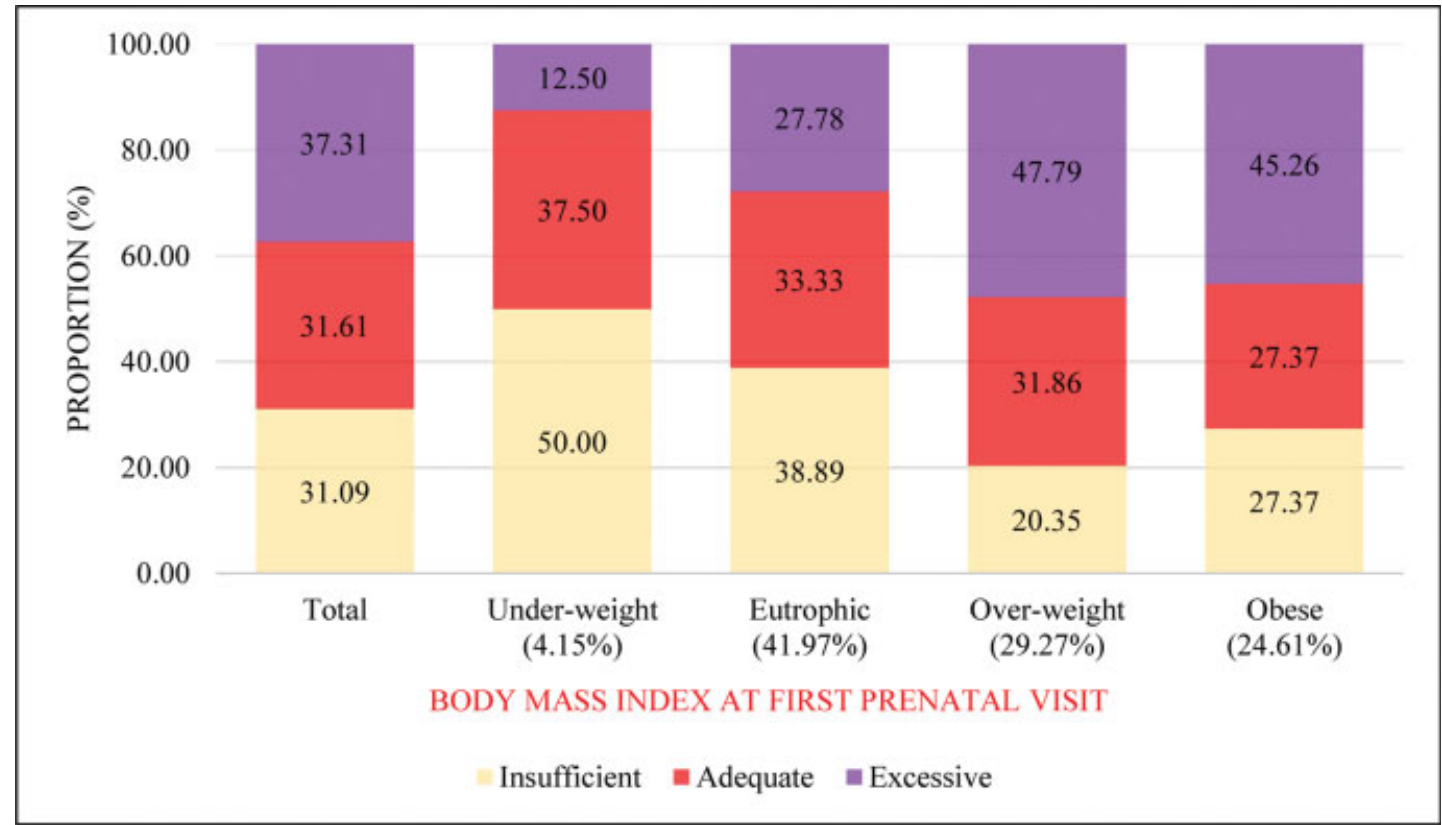

Fig. 1 Prevalence of insufficient, adequate and excessive gestational weight gain by maternal body mass index at first prenatal visit ( $\leq 14$ weeks).

Table 2 Percentage distribution of health-related behaviors in the whole sample

\begin{tabular}{|c|c|c|c|c|c|}
\hline Variable (n) & $N(386)$ & $\%$ & Variable (n) & $N(386)$ & $\%$ \\
\hline Sleep time & & & Food Intake (days/week) & & \\
\hline Sleep Hours $<7$ & & & Vegetable intake (383) & & \\
\hline Before pregnancy (383) & 146 & 38.12 & 7 & 187 & 48.83 \\
\hline Beginning of pregnancy (383) & 126 & 32.90 & $3-6$ & 62 & 16.19 \\
\hline \multirow[t]{2}{*}{ End of pregnancy (379) } & 225 & 59.37 & $1-3$ & 102 & 26.63 \\
\hline & & & Never or $<1$ & 32 & 8.36 \\
\hline Physical Activity & & & Fruit Intake (386) & & \\
\hline \multirow[t]{2}{*}{ Sedentary lifestyle (379) } & 215 & 57.03 & 7 (ref.) & 186 & 48.19 \\
\hline & & & $3-6$ & 69 & 17.88 \\
\hline Unhealthy behaviors & & & $1-3$ & 99 & 25.65 \\
\hline Alcohol intake (383) & 31 & 8.09 & Never or $<1$ & 32 & 8.29 \\
\hline \multirow[t]{2}{*}{ Smoking- last 2 years (381) } & 64 & 16.80 & Milk/dairy products intake (386) & & \\
\hline & & & 7 & 246 & 63.73 \\
\hline Psychosocial History & & & $3-6$ & 41 & 10.62 \\
\hline EPDS (381) & & & $1-3$ & 61 & 15.80 \\
\hline$<10$ & 226 & 59.32 & Never or $<1$ & 38 & 9.84 \\
\hline \multirow[t]{2}{*}{$\geq 10$} & 155 & 40.68 & Meat intake (385) & & \\
\hline & & & Never or $<1$ & 15 & 3.9 \\
\hline PSS (374) & & & $1-3$ & 58 & 15.06 \\
\hline$<20$ & 242 & 64.71 & $3-6$ & 62 & 16.10 \\
\hline \multirow[t]{2}{*}{$\geq 20$} & 132 & 35.29 & 7 (ref.) & 250 & 64.94 \\
\hline & & & Soft drink intake (386) & & \\
\hline LOT-R (376) Mean \pm SD & 15.67 & \pm 3.22 & Never or $<1$ & 137 & 35.49 \\
\hline Food Intake (number of tins) & & & $1-3$ & 105 & 27.20 \\
\hline Family oil consumption (379) & & & $3-6$ & 60 & 15.54 \\
\hline$<1$ & 108 & 28.50 & 7 & 84 & 21.76 \\
\hline 1 & 108 & 28.50 & Beans intake (382) & & \\
\hline $2-3$ & 128 & 33.77 & 7 (ref.) & 169 & 44.24 \\
\hline \multirow[t]{3}{*}{$>3$} & 35 & 9.23 & $3-6$ & 48 & 12.56 \\
\hline & & & $1-3$ & 106 & 27.74 \\
\hline & & & Never or $<1$ & 59 & 15.44 \\
\hline
\end{tabular}

Abbreviations: EPDS: Edinburgh Postpartum Depression Scale. PSS: Perceived Stress Scale. LOT-R: Revised Life Orientation Test.

One tin $=900 \mathrm{ml}$. Data were presented as frequencies $(\mathrm{n})$ and percentages $(\%)$. 
Table 3 Unadjusted risk factors (sociodemographic, obstetric and health-related behavior factors) for excessive gestational weight gain in women with overweight and obesity

\begin{tabular}{|c|c|c|c|c|c|c|c|c|}
\hline Variable & OR & $95 \% \mathrm{Cl}$ & Variable & OR & $95 \% \mathrm{Cl}$ & Variable & O.R. & $95 \% \mathrm{Cl}$ \\
\hline & & & $\begin{array}{l}\text { Meat intake } \\
\text { (days/week) }\end{array}$ & & & $\begin{array}{l}\text { Family consumption of } \\
\text { oil (number of tins) }\end{array}$ & & \\
\hline $\begin{array}{l}\text { Maternal Age } \\
\text { (years old) }\end{array}$ & 1.01 & $0.97-1.05$ & Never or $<1$ & 0.73 & $0.20-2.66$ & $<1$ (ref.) & 1.00 & - \\
\hline \multirow[t]{2}{*}{ Multiparity } & 1.13 & $0.69-1.84$ & $1-3$ & 1.01 & $0.53-1.95$ & 1 & 1.54 & $0.81-2.95$ \\
\hline & & & $3-6$ & 0.93 & $0.49-1.77$ & $2-3$ & 1.59 & $0.85-2.97$ \\
\hline \multirow[t]{2}{*}{ Pre-pregnancy NCD } & 1.25 & $0.75-2.11$ & 7 (ref.) & 1.00 & - & $>3$ & 2.30 & $0.98-5.37$ \\
\hline & & & Beans & & & $\begin{array}{l}\text { Vegetable intake } \\
\text { (days/ week) }\end{array}$ & & \\
\hline $\begin{array}{l}\text { Smoking in the } \\
\text { last } 2 \text { years }\end{array}$ & 0.89 & $0.48-1.68$ & 7 (ref.) & 1.00 & - & 7 (ref.) & 1.00 & - \\
\hline Sedentary lifestyle & 1.23 & $0.78-1.95$ & $3-6$ & 0.80 & $0.35-1.79$ & $3-6$ & 1.21 & $0.61-2.39$ \\
\hline \multirow{2}{*}{$\begin{array}{l}\text { Alcohol intake } \\
\text { during pregnancy }\end{array}$} & 0.30 & $0.09-1.01$ & $1-3$ & 1.30 & $0.74-2.27$ & $1-3$ & 1.51 & $0.86-2.63$ \\
\hline & & & Never or $<1$ & 1.91 & $1.01-3.63$ & Never or $<1$ & 2.95 & $1.35-6.46$ \\
\hline Educational level & & & $\begin{array}{l}\text { Fruit Intake } \\
\text { (days/week) }\end{array}$ & & - & Sleep Hours $<7$ & & \\
\hline Elementary school & 1.08 & $0.61-1.91$ & 7 (ref.) & 1.00 & $0.61-2.21$ & Before pregnancy & 0.93 & $0.58-1.50$ \\
\hline High school (ref.) & 1.00 & - & $3-6$ & 1.16 & $0.89-2.67$ & Beginning of pregnancy & 0.90 & $0.55-1.49$ \\
\hline \multirow[t]{2}{*}{ Advanced degree } & 0.93 & $0.48-1.79$ & $1-3$ & 1.54 & $0.59-3.22$ & Final of pregnancy & 0.94 & $0.59-1.51$ \\
\hline & & & Never or $<1$ & 1.38 & & & & \\
\hline $\begin{array}{l}\text { Soft drink intake } \\
\text { (days/week) }\end{array}$ & & & \multicolumn{2}{|l|}{$\begin{array}{l}\text { Milk and dairy } \\
\text { products intake } \\
\text { (days/ week) }\end{array}$} & & LOT-R & 0.97 & $0.90-1.04$ \\
\hline Never (ref.) & 1.00 & - & 7 (ref.) & 1.00 & - & EPDS & & \\
\hline$<1$ & 2.05 & $0.81-5.18$ & $3-6$ & 0.88 & $0.41-1.89$ & $<10$ (ref.) & 1.00 & - \\
\hline $1-3$ & 2.02 & $0.81-5.03$ & $1-3$ & 0.89 & $0.47-1.70$ & & & \\
\hline $3-6$ & 1.32 & $0.47-3.69$ & Never or $<1$ & 0.51 & $0.21-1.28$ & $\geq 10$ & 1.18 & $0.74-1.89$ \\
\hline \multirow[t]{2}{*}{7} & 1.99 & $0.78-5.10$ & & & & PSS & & - \\
\hline & & & & & & $<20$ (ref.) $\geq 20$ & 1.63 & $1.01-2.64$ \\
\hline
\end{tabular}

Abbreviations: $\mathrm{Cl}$, confidence interval; EPDS, Edinburgh Portpartum Depression.Scale; LOT-R, Revised Life Orientation Test; NCD, noncommunicable disease; OR, odds ratio; PSS, Perceived Stress Scale; Ref, reference level.

Excessive gestational weight gain (GWG) in overweight and obese women $(n=97)$, remaining sample $(n=289)$. One tin $=900 \mathrm{ml}$. Data were analyzed by logistic regression analyses.

such as beans, fruits, and vegetables. ${ }^{29}$ In the habitual Brazilian diet, beans and meat are responsible for the majority of iron intake, which is described as the principal immediate factor to anemia. ${ }^{30}$ Moreover, a diet pattern rich in fish, beans, nuts, and yogurt has been shown to decrease the risk of inadequate GWG. ${ }^{31}$

Most women in the present study were overweight or obese, and consistent with other studies, ${ }^{32,33}$ the highest prevalence of excessive GWG occurred among women that were overweight or obese.

We did not determine that SSD was associated with excessive GWG in women with overweight and obesity. In contrast, one study that objectively assessed sleep duration demonstrated that excessive GWG was associated with SSD and more sleep disruption among prepregnancy overweight women. ${ }^{34}$
Notably, some study limitations should be considered upon interpreting our results. First, our study is limited by the use of non-quantitative assessment of dietary intake, which precludes the estimation of caloric, macronutrient, and micronutrient intake. Second, sleep duration was selfreported rather than measured, and sleep quality is unknown. Lastly, our study has a cross-sectional design. As a result, the simultaneous exposure and outcome assessment does not allow for the establishment of a temporal relationship between exposure and outcome.

In summary, our findings highlight that some dietary patterns during pregnancy (e.g., low vegetable and bean intake) and stress may contribute to excessive GWG in overweight and obese women. Although these findings should be confirmed by further studies, pregnancy is a powerful impetus for positive behavioral change. Based on 
The Role of Health-related Behaviors in Gestational Weight Gain among Women with Overweight and 322 Obesity Paulino et al.

Table 4 Adjusted risk factors for excessive gestational weight gain in women with overweight and obesity

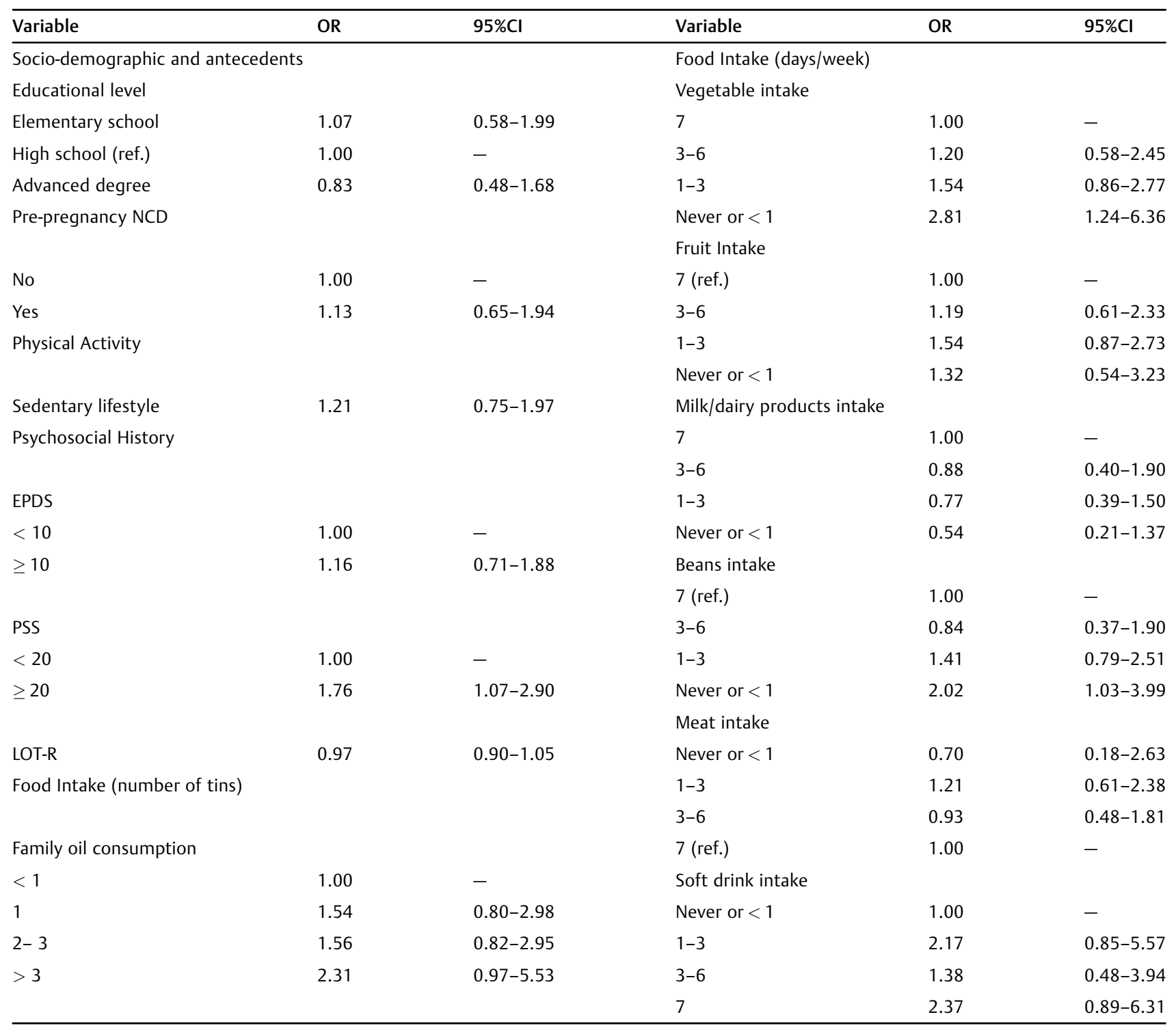

Abbreviations: $\mathrm{Cl}$, confidence interval; EPDS, Edinburgh Portpartum Depression.Scale; LOT-R, Revised Life Orientation Test; NCD, noncommunicable disease; OR, odds ratio; Ref, reference level.

Excessive gestational weight gain (GWG) in overweight and obese women $(n=94)$, remaining sample $(n=277)$. One tin $=900 \mathrm{ml}$. Data were analyzed by logistic regression analyses adjusted by maternal age, multiparity, sleep duration, smoking and alcohol intake.

Table 5 Multivariate logistic regression analysis between adjusted risk factors and excessive gestational weight gain in women with overweight and obesity

\begin{tabular}{llll}
\hline Variable & p-value & OR & $95 \% \mathrm{Cl}$ \\
\hline PSS (Stress) & & & - \\
$<20$ (ref.) & - & 1.00 & $1.03-2.96$ \\
$\geq 20$ & 0.037 & 1.75 & \\
\hline
\end{tabular}

Abbreviations: OR, Odds Ratio; Cl, confidence interval; PSS: Perceived Stress Scale; Ref, reference level.

Excessive gestational weight gain (GWG) in overweight and obese women $(n=83)$, remaining sample $(n=249) .$. Multivariate logistic regression adjusted by maternal age, multiparity, sleep duration, smoking and alcohol intake. Independent variables considered: pre-pregnancy noncommunicable disease (no: 0 , yes: 1 ); physical activity (no: 1, yes: 0 ); maternal education level (elementary: 1 , high school: 0 , advanced degree: 2 ); soft drink intake (never or <1 day/week: 0, 1-3 days/week: 1, 3-6 days/week: 2, 7 days/week: 3); meat intake (never or $<1$ day/week: 1, 1-3 days/week: 2, 3-6 days/week: 3, 7 days/week: 0 ); beans intake (never or $<1$ day/week: 1, 1-3 days/week: 2, 3-6 days/week: 3, 7 days/week: 0); fruit intake (never or < 1 day/week: 1, 1-3 days/week: 2, 3-6 days/week: 3, 7 days/week: 0); milk intake (never or $<1$ day/week: 1, 1-3 days/week: 2, 3-6 days/week: 3, 7 days/week: 0 ); vegetable intake (never or $<1$ day/week: 1, 1-3 days/week: 2, 3-6 days/week: 3, 7 days/week: 0); family oil consumption ( $<1$ tin: 0, 1 tin: 1, 2-3 tin: 2, $>3$ : 3); LOTR (continuous variable), EPDS $(<10: 0, \geq 10: 1)$ and PSS $(<20: 0, \geq 20: 1)$. 
our results, a multidisciplinary approach - especially with nutritional attention and psychologist support - should be used for overweight and obese women to promote adequate GWG and optimize antenatal care.

\section{Conclusion}

Among women with overweight and obesity, health-related behavior stress is the main variable associated with excessive GWG. Low vegetable and beans consumption during pregnancy (no intake or intake less than once per week) also showed strong association with excessive GWG. The current findings provide information that can be used to design intervention programs for women with overweight and obesity in early pregnancy to improve maternal and child health on the basis that pregnancy is an ideal window of opportunity for women to adopt healthier lifestyles. Further studies, with a larger and multicenter cohort, should be conducted to confirm these data.

\section{Contributions}

Paulino D. S. M., Pinho-Pompeu M. and Surita F. G. designed the research; data collection was performed by Paulino D. S. M., Pinho-Pompeu M. Jesus J. V. and Surita F. G; Machado H. C. performed the statistical analysis; Paulino D. S. M., Pinho-Pompeu M., Machado H. C. and Surita F. G. analyzed and compiled the data; Paulino D. S. M.,, Surita F. G. Pinho-Pompeu M., and Jesus J. V. wrote the paper; Paulino D. S. M. and Surita F. G. had primary responsibility for the final content.

\section{Conflict of Interests}

The authors have no conflict of interest to declare.

Acknowledgments

The authors thank the Reproductive Health and Healthy Habits (SARHAS, in the Portuguese acronym) research group members, who provided helpful comments.

\section{References}

1 Black RE, Victora CG, Walker SP, Bhutta ZA, Christian P, de Onis M, Ezzati M, et al; Maternal and Child Nutrition Study Group. Maternal and child undernutrition and overweight in low-income and middle-income countries. Lancet. 2013;382(9890):427-451. Doi: 10.1016/S0140-6736(13)60937-X

2 Spencer SJ. Early life programming of obesity: the impact of the perinatal environment on the development of obesity and metabolic dysfunction in the offspring. Curr Diabetes Rev. 2012;8(01): 55-68. Doi: 10.2174/157339912798829214

3 Kominiarek MA, Peaceman AM. Gestational weight gain. Am J Obstet Gynecol. 2017;217(06):642-651. Doi: 10.1016/j.ajog. 2017.05.040

4 McDowell M, Cain MA, Brumley J. Excessive gestational weight gain. J Midwifery Womens Health. 2019;64(01):46-54. Doi: 10.1111/jmwh.12927

5 Kapadia MZ, Gaston A, Van Blyderveen S, Schmidt L, Beyene J, McDonald H, McDonald SD. Psychological antecedents of excess gestational weight gain: a systematic review. BMC Pregnancy Childbirth. 2015;15:107. Doi: 10.1186/s12884-015-0535-y
6 Faria-Schützer DB, Surita FG, Nascimento SL, Vieira CM, Turato E. Psychological issues facing obese pregnant women: a systematic review. J Matern Fetal Neonatal Med. 2017;30(01):88-95. Doi: 10.3109/14767058.2016.1163543

7 Plante AS, Lemieux S, Labrecque M, Morisset AS. Relationship between psychosocial factors, dietary intake and gestational weight gain: a narrative review. J Obstet Gynaecol Can. 2019;41 (04):495-504. Doi: 10.1016/j.jogc.2018.02.023

8 Muktabhant B, Lawrie TA, Lumbiganon P, Laopaiboon M. Diet or exercise, or both, for preventing excessive weight gain in pregnancy. Cochrane Database Syst Rev. 2015;(06):CD007145. Doi: 10.1002/14651858.CD007145.pub3

9 St-Onge MP. Sleep-obesity relation: underlying mechanisms and consequences for treatment. Obes Rev. 2017;18(Suppl 1):34-39. Doi: 10.1111/obr.12499

10 Cedernaes J, Schiöth HB, Benedict C. Determinants of shortened, disrupted, and mistimed sleep and associated metabolic health consequences in healthy humans. Diabetes. 2015;64(04):1073-1080. Doi: 10.2337/db14-1475

11 Felder JN, Laraia B, Coleman-Phox K, Bush N, Suresh M, Thomas M, et al. Poor sleep quality, psychological distress, and the buffering effect of mindfulness training during pregnancy. Behav Sleep Med. 2018;16(06):611-624. Doi: 10.1080/15402002.2016.1266488

12 Levine MD, Cheng Y, Cluss PA, Marcus MD, Kalarchian MA. Prenatal smoking cessation intervention and gestational weight gain. Womens Health Issues. 2013;23(06):e389-e393. Doi: 10.1016/j.whi.2013.07.005

$13 \mathrm{Li} \mathrm{Y}$, Wang $\mathrm{H}$. In utero exposure to tobacco and alcohol modifies neurobehavioral development in mice offspring: consideration a role of oxidative stress. Pharmacol Res. 2004;49(05):467-473. Doi: 10.1016/j.phrs.2003.11.002

14 Faria-Schützer DB, Surita FGC, Alves VLP, Vieira CM, Turato ER. Emotional experiences of obese women with adequate gestational weight variation: a qualitative study. PLoS One. 2015;10(11): e0141879. Doi: 10.1371/journal.pone.0141879

15 McDonald SD, Park CK, Timm V, Schmidt L, Neupane B, Beyene J. What psychological, physical, lifestyle, and knowledge factors are associated with excess or inadequate weight gain during pregnancy? A cross-sectional survey. J Obstet Gynaecol Can. 2013;35 (12):1071-1082. Doi: 10.1016/S1701-2163(15)30757-X

16 Institute of Medicine, National Research Council. Weight gain during pregnancy: reexamining the guidelines. Washington (DC): National Academies Press; 2009

17 Villar J, Cheikh Ismail L, Victora CG, Ohuma EO, Bertino E, Altman DG, et al; International Fetal and Newborn Growth Consortium for the 21 st Century (INTERGROWTH-21st). International standards for newborn weight, length, and head circumference by gestational age and sex: the Newborn Cross-Sectional Study of the INTERGROWTH-21st Project. Lancet. 2014;384(9946): 857-868. Doi: 10.1016/S0140-6736(14)60932-6

18 Jaime PC, Stopa SR, Oliveira TP, Vieira ML, Szwarcwald CL, Malta DC. Prevalence and sociodemographic distribution of healthy eating markers, National Health Survey, Brazil 2013. Epidemiol Serv Saude. 2015;24(02):267-276. Doi: 10.5123/S1679-49742 015000200009

19 Ministério da Saúde. Secretaria de Atenção à Saúde. Departamento de Atenção Básica [Internet]. Orientações para avaliação de marcadores de consumo alimentar na atenção básica. Brasília (DF): Ministério da Saúde; 2015 [cited 2019 Mar 11]. Available from: http://bvsms.saude.gov.br/bvs/publicacoes/marcadores_consumo_alimentar_atencao_basica.pdf

20 Cox JL, Holden JM, Sagovsky R. Detection of postnatal depression. Development of the 10-item Edinburgh Postnatal Depression Scale. Br J Psychiatry. 1987;150:782-786. Doi: 10.1192/bjp.150.6.782

21 Roberti JW, Harrington LN, Storch EA. Further psychometric support for the 10-item version of the Perceived Stress Scale. J Coll Couns. 2011;9(02):135-147. Doi: 10.1002/j.2161-1882.2006.tb00100.x 
The Role of Health-related Behaviors in Gestational Weight Gain among Women with Overweight and

22 Scheier MF, Carver CS, Bridges MW. Distinguishing optimism from neuroticism (and trait anxiety, self-mastery, and selfesteem): a reevaluation of the Life Orientation Test. J Pers Soc Psychol. 1994;67(06):1063-1078. Doi: 10.1037//0022-3514.67. 6.1063

23 Kominiarek MA, Grobman W, Adam E, Buss C, Culhane J, Entringer $\mathrm{S}$, et al. Stress during pregnancy and gestational weight gain. J Perinatol. 2018;38(05):462-467. Doi: 10.1038/ s41372-018-0051-9

24 Matthews J, Huberty J, Leiferman J, Buman M. Psychosocial predictors of gestational weight gain and the role of mindfulness. Midwifery. 2018;56:86-93. Doi: 10.1016/j.midw.2017.10.008

25 Loh J, Harms C, Harman B. Effects of parental stress, optimism, and health-promoting behaviors on the quality of life of primiparous and multiparous mothers. Nurs Res. 2017;66(03):231-239. Doi: 10.1097/NNR.0000000000000219

26 Shin D, Bianchi L, Chung H, Weatherspoon L, Song WO. Is gestational weight gain associated with diet quality during pregnancy? Matern Child Health J. 2014;18(06):1433-1443. Doi: 10.1007/s10995-013-1383-X

27 Olson CM, Strawderman MS. Modifiable behavioral factors in a biopsychosocial model predict inadequate and excessive gestational weight gain. J Am Diet Assoc. 2003;103(01):48-54. Doi: 10.1053/jada.2003.50001
28 Bärebring L, Brembeck P, Löf M, Brekke HK, Winkvist A, Augustin $\mathrm{H}$. Food intake and gestational weight gain in Swedish women. Springerplus. 2016;5:377. Doi: 10.1186/s40064-016-2015-X

29 Instituto Brasileiro de Geografia e Estatística. Pesquisa de orçamentos familiares 2008-2009: análise do consumo alimentar pessoal no Brasil. Rio de Janeiro: IBGE; 2011

30 Szarfarc SC, de Souza SB. Prevalence and risk factors in iron deficiency and anemia. Arch Latinoam Nutr. 1997;47(02, Suppl 1):35-38

31 Wei X, He JR, Lin Y, Lu M, Zhou Q, Li S, et al. The influence of maternal dietary patterns on gestational weight gain: A large prospective cohort study in China. Nutrition. 2019;59:90-95. Doi: 10.1016/j.nut.2018.07.113

32 Chu SY, Callaghan WM, Bish CL, D’Angelo D. Gestational weight gain by body mass index among US women delivering live births, 2004-2005: fueling future obesity. Am J Obstet Gynecol. 2009;200 (03):271.e1-271.e7. Doi: 10.1016/j.ajog.2008.09.879

33 Faucher MA, Barger MK. Gestational weight gain in obese women by class of obesity and select maternal/newborn outcomes: A systematic review. Women Birth. 2015;28(03):e70-e79. Doi: 10.1016/j. wombi.2015.03.006

34 Gay CL, Richoux SE, Beebe KR, Lee KA. Sleep disruption and duration in late pregnancy is associated with excess gestational weight gain among overweight and obese women. Birth. 2017;44 (02):173-180. Doi: 10.1111/birt.12277 